\title{
A VISÃO ETNOECOLÓGICA QUE JOVENS EM FORMAÇÃO ESCOLAR TÊM SOBRE OS ANFÍBIOS E A IMPORTÂNCIA DA EDUCAÇÃO AMBIENTAL PARA CONSERVAÇÃO DESTES ANIMAIS
}

\author{
THE ETHNOECOLOGICAL VIEW THAT HIGH SCHOOL YOUNG'S HAVE ON \\ AMPHIBIANS AND THE IMPORTANCE OF ENVIRONMENTAL EDUCATION FOR THE \\ CONSERVATION OF THESE ANIMALS \\ Lucas FERRANTE ${ }^{1 *}$ e Carina VEIGA ${ }^{2}$
}

${ }^{1}$ Instituto Nacional de Pesquisas da Amazônia (INPA), CEP 69060-001, Manaus - AM, Brasil. ²Universidade Fundação de Ensino Octávio Bastos (UNIFEOB), CEP 13874-159, São João da Boa Vista - SP, Brasil. *lucasferrante@ hotmail.com

\begin{abstract}
RESUMO
Os anfíbios são os animais mais ameaçados entre os vertebrados e no Brasil são registrados vários declínios e extinções para estes animais. Entre as principais ameaças, estão perda e fragmentação de hábitats, expansão da agricultura, poluição, doenças e mudanças climáticas. Esforços conservacionistas bem-sucedidos integram a comunidade em seus planos de ação, entretanto, os anfíbios geralmente são vistos pela sociedade como animais venenosos e transmissores de doenças, muitas vezes associados à bruxaria ou superstições. Neste trabalho, nós avaliamos a percepção etnoecológica que alunos de uma turma do ensino médio têm sobre os anfíbios anuros, verificando como estes animais são vistos. Após a avaliação, realizamos uma intervenção de educação ambiental para desmistificar os mitos e lendas que rondam estes animais, com a finalidade de estimular um caráter ecológico e conservacionista em alunos que antes tinham uma visão negativa. Com resultados bem-sucedidos, nossos dados indicam ser possível mudar a visão estigmatizada que a sociedade tem sobre esses animais e conscientizar para a conservação deste grupo.
\end{abstract}

PALAVRAS-CHAVE: anfíbios; anuros; educação ambiental; conservação; etnobiologia

\begin{abstract}
Amphibians are the most threatened animals among vertebrates and in Brazil several declines and extinctions are recorded for these animals. Among the main threats are habitat losses, fragmentation, expansion of agriculture, pollution, disease, and climate changes. Successful conservation efforts integrate the community into their action plans. However, amphibians are often viewed by society as venomous animals and disease transmitters, often associated with witchcraft or superstition. In this work, we evaluate the ethnoecological perception that students of a high school class have about amphibians, verifying how these animals are seen. After the evaluation we performed an environmental education intervention to demystify the myths and legends that surround these animals, with the purpose of stimulating an ecological and conservationist character in students who previously had a negative view. With successful results, our data indicate that it is possible to change the stigmatized view that society has about these animals and to raise awareness for the conservation of this group.
\end{abstract}

KEYWORDS: amphibians, anurans; environmental education; conservation; ethnobiology

\section{INTRODUÇÃO}

Os anfíbios são os animais mais ameaçados de acordo com as avaliações da Lista Vermelha de Espécies Ameaçadas da União Internacional para a Conservação da Natureza (IUCN, 2019). Para o Brasil e outros países das Américas do Sul e Central, registros de declínios e extinções de populações de anfíbios são registrados devido à poluição, doenças, queimadas, mudanças climáticas, perda e fragmentação de seu habitat natural, agricultura e uso intensivo de agrotóxicos (BOLAÑOS et al., 2008; FERRANTE et al., 2017a; FERRANTE et al., 2019a). 
Eles são animais geralmente inofensivos e fáceis de encontrar na natureza devido a sua abundância, sendo que, com frequência, sapos, rãs e pererecas são o primeiro contato de muitas crianças com a vida animal, estimulando sua relação com a natureza (COX et al., 2008). Entretanto, estudantes de diferentes faixas etárias, em escolas vizinhas a uma área de proteção na região Amazônica, apresentaram uma visão negativa sobre os sapos, onde mesmo seus professores compartilharam desta opinião sobre estes animais (PONTES-DA-SILVA et al., 2016). Anfíbios são muito estigmatizados e envoltos em lendas e mitos por diferentes parcelas da população (CASCUDO, 2004; LEITE, 2004; FERRANTE, 2016b; PONTES-DA-SILVA et al., 2016). Reverter o estigma que a população tem sobre os anfíbios é excencial se desejamos conservar este grupo (FERRANTE et al. 2017b), visando a formar tomadores de decisões mais concientes que considerem as ameaças sobre a fauna (FERRANTE, 2016; FERRANTE et al. 2019b).

Múltiplas ações de educação ambiental têm objetivado reverter a visão estigmatizada que diferentes parcelas da população têm sobre os anfíbios, como os trabalhos de Ferrante, (2016a, 2016b), Ferrante e Najar (2016), Ferrante et al. (2017b) e Ferrante et al. (2019b). Entretanto, o sucesso destas atividades nunca foi medido. Crianças e jovens sob a orientação de atividades educativas em zoológicos apresentam resultados positivos sobre a biologia da conservação e ensino de ciências, comparados a jovens e crianças que embora tenham contato com animais, não receberam qualquer orientação sobre $o$ tema (JENSEN, 2013), o que enfatiza a importancia de ações que trabalhem a importância da conservação dos anfíbios com jovens em formação escolar. Jovens que recebam orientação científica em relação aos anfíbios poderiam ainda se tornar futuros pesquisadores do tema e contribuir para a conservação destes animais (FERRANTE e NAJAR, 2016).

Iniciativas de conservação bem-sucedidas devem integrar todos os setores da sociedade, envolvendo pessoas de múltiplas faixas etárias, inclusive estudantes, sendo esta talvez a solução para a crise global de extinções dos anfíbios e demais problemas ambientais (FERRANTE, 2016a). Neste grave cenário que muitas populações de anfíbios enfrentam por todo o mundo, talvez nenhuma ação seja tão importante e urgente em favor da causa dos anfíbios como iniciativas de educação ambiental e conscientização (ANGULO e GRIFFITHS, 2010). Devido aos vários declínios populacionais e extinções locais de espécies de anfíbios registrados no Sudeste do Brasil, como reportados por FERRANTE et al.( 2017a) e FERRANTE et al. (2019a), torna-se relevante compreender a visão da população sobre estes animais nesta região. Desta forma, nós avaliamos a percepção etnoecológica que uma turma do segundo ano do ensino médio, em uma escola particular inserida em uma área urbana da região Sudeste do país, tem sobre os anfíbios e o potencial da educação ambiental para mudar os estigmas que envolvem estes animais.

\section{MÉTODOS}

Nós avaliamos uma turma de 44 alunos do segundo ano do ensino médio de uma mesma sala em uma escola particular na cidade de São João da Boa Vista, Estado de São Paulo, Sudeste do Brasil. A metodologia do trabalho foi dividida em três partes. A primeira consistiu na aplicação de um questionário etnoecológico a priori contendo dez questões sobre cultura, mitologia, história natural, comportamento e conservação de anfíbios. Em seguida, foi ministrada uma aula de educação ambiental abordando o ciclo de vida, biologia e conservação de anfíbios na mesma turma avaliada. A terceira parte envolveu a aplicação de um segundo questionário contendo as mesmas perguntas do questionário inicial, com exceção de duas questões não foram reavaliadas a posteriori (questões 1 e 2) por serem de senso da cultura dos alunos envolvendo os anfíbios. Toda a atividade ocorreu durante a primeira semana do mês de agosto de 2015.

\section{Questionário etnobiológico sobre anfíbios}

A escolha dos alunos foi intencional por esta série do ensino médio abordar conteúdos sobre zoologia e ecologia na disciplina de Biologia. Por meio de questionários aplicados, foram levantadas as visões etnoecológicas a priori e a posteriori da intervenção de educação ambiental. O questionário composto por dez questões foi dividido em dois grupos de perguntas, um com quatro perguntas de cunho pessoal e cultural dos alunos envolvendo os anfíbios (Quadro 1) e outro com seis perguntas teóricas acerca da ecologia de anfíbios e a relação que estes animais têm com o meio ambiente (Quadro 2). As duas primeiras questões da tabela 1 , referentes aos motivos que os estudantes atribuem o medo dos anfíbios e os mitos que envolvem estes animais, foram aplicadas apenas nos questionários a priori. 
Quadro 1- Perguntas de cunho pessoal

\begin{tabular}{|l|l|}
\hline 1 & Em sua opinião, por que algumas pessoas não gostam ou sentem medo desses animais? \\
\hline 2 & Você já ouviu algum mito sobre os sapos? Se sim, qual? \\
\hline 3 & Se você encontrasse um sapo, qual seria sua reação? \\
\hline 4 & Se você encontrasse esses animais em situação de perigo, o que você faria? \\
\hline
\end{tabular}

Para as questões de cunho pessoal, foram comparadas as porcentagens das respostas a priori e a posteriori, verificando a mudança nas respostas e suas proporções em cada questionário.

Quadro 2- Perguntas teóricas sobre ecologia de anfíbios e sua relação com o meio ambiente

\begin{tabular}{|l|l|}
\hline 1 & O que significa a palavra anfíbio? \\
\hline 2 & $\begin{array}{l}\text { Sabendo que os girinos são a primeira fase de propagação de sapos, rãs e pererecas, explique a relação } \\
\text { desse desenvolvimento envolvendo a poluição de seu habitat. }\end{array}$ \\
\hline 3 & Na sua concepção, existe diferença entre sapos, rãs ou pererecas? \\
\hline 4 & Você sabe por que esses animais cantam (coaxam) durante a noite? \\
\hline 5 & Você sabe qual a importância desses animais para o meio ambiente? \\
\hline 6 & De que forma você coopera para a conservação do meio ambiente? \\
\hline
\end{tabular}

As seis questões sobre ecologia e conservação de anfíbios foram avaliadas de forma qualitativa, com pontuação de 0 a 10, onde: 0 até $2=$ Não Compreende (NC); 3 até $4=$ Compreende Pouco (CP); 5 até $6=$ Compreende Razoavelmente (CR); 7 até $8=$ Compreende Bem (CB); 9 até $10=$ Tem Plena Compreensão (TPC). Desta forma, realizamos uma comparação entre os questionários a priori e $a$ posteriori por meio de um gráfico de boxplot com desvio padrão.

\section{Uma intervenção de educação ambiental sobre os anfíbios}

A aula de educação ambiental consistiu em uma exposição de slides com duração de 40 minutos. A apresentação foi dividida em 15 slides, o primeiro apresentava o grupo lissanfíbia que constitui os grupos de anfíbios atuais, os quais são representados por anuros, cecílias e salamendras (DUELLMAN e TRUEB, 1996). O segundo abordou o ciclo de vida dos anfíbios, destacando a diferença físiológica entre girinos e anfíbios pós-metamorficos. Outro slide apresentou os anuros, mostrando a diferença entre sapos, rãs e pererecas, sendo os sapos anuros terrestres, normalmente com pele seca e rugosa; pererecas sendo anuros árboreos, com discos adesivos nas pontas dos dedos para facilitar a escalada; e rãs sendo anuros com hábitos aquáticos mesmo pós-metamorfose, com pele úmida e patas trazeiras bem desenvolvidas para nadar ou dar saltos longos. Entre o sexto e nono slides foram abordados as diferenças comportamentais e o uso de habitats entre sapos, rãs e pererecas, bem como os métodos de locomoção. O décimo slide abordou a comunicação dos anfíbios, com ênfase nos anuros.

Em sequência, apresentaram-se os diferentes tipos de cantos dos anuros, como canto de corte (utilizado por machos para atrair as fêmeas), canto territorial (entre dois machos para defensa de território) e canto agonístico (canto normalmente observado em eventos de predação) (DUELLMAN e TRUEB, 1996; WELLS, 2007). A seguir, discorreu-se sobre o papel do canto do macho na corte da fêmea e o ciclo de vida dos animais, como o amplexo e deposição dos ovos em poças temporárias na estação da chuva no caso dos sapos, como a espécie Procerathoprys boiei que ocorre na região (FERRANTE, 2019), construção de ninhos de folhas no alto das árvores sobre poças por pererecas da familia Phyllomedusidae, que ocorrem por todo o Brasil (NAJAR e FERRANTE, 2018) e ninhos de espuma por rãs (DUELLMAN e TRUEB, 1996; WELLS, 2007).

O décimo segundo slide introduziu os grandes declínios de anfíbios pelo mundo e suas causas, como destruição do habitat, poluição e doenças infecciosas como o fungo letal Batrachochytrium dendrobatidis (BOLAÑOS et al., 2008; ANGULO e GRIFFITHS, 2010). Neste ponto da aula, as lendas sobre anfíbios também foram discutidas, tentando desmistificar as crenças dos alunos com base nas informações biológicas e ecológicas vistas até o momento. Para finalizar, foi apresentada a importância 
ecológica dos anfíbios, como controle natural de pragas e vetores de doenças para o ser humano (CORTÉS-GOMEZ et al. 2015), função bioindicadora (SILVANO et al. 2005), uso na culinária como a rã-touro americana que é consumida em várias partes do mundo, inclusive no Brasil (COX et al. 2008; IUCN, 2015) e a importância médica dos anfíbios, como uso de polipepitídios presentes na pele dos anfíbios utilizados para a produção de fármacos (COX et al. 2008). Finalizando a aula, foi mostrada a variedade de formas e cores que compõem a beleza dos anfíbios anuros tanto em girinos quanto nos adultos.

\section{RESULTADOS E DISCUSSÃO}

De acordo com a avaliação aplicada aos alunos deste estudo, a aparência dos anfíbios, o nojo que as pessoas sentem destes animais e as crenças que os envolvem são apontados como os principais motivos para as pessoas terem medo ou não gostarem destes animais. Outros motivos também foram relatados pelos alunos, como o canto, o fato dos sapos pularem e até mesmo a falta de convívio e conhecimento sobre estes animais (Figura 1a).

Sobre as lendas e mitos que envolvem os anfíbios (Figura 1b), 50\% dos alunos nunca ouviram nenhum tipo de mito ou lenda sobre os sapos ou não souberam responder a respeito. Como principal resposta a esta pergunta, $18 \%$ disseram que os sapos podem esguichar seu veneno nos olhos das pessoas que se aproximem. Entretanto, a habilidade de soltar o veneno voluntariamente é observada apenas no bufonídeo Rhaebo guttatus, sendo a única espécie relatada a possuir esta habilidade (JARED et al., 2011). Essa espécie não ocorre na região Norte do país, na bacia Amazônica (AZEVEDO-RAMOS et al., 2010). Desta forma, nós levantamos duas hipóteses para a presença deste mito na região: a primeira é que a lenda migrou da região Norte do país, difundindo-se na cultura local; e a segunda seria a possibilidade de que outras espécies de bufonídeos brasileiros que habitem a região também possuam esta habilidade, sendo que até o momento não tenha sido registrada pela ciência. Outras quatro espécies de bufonídeos ocorrem na região, sendo todas muito abundantes e habitando tanto áreas abertas quanto florestais (HADDAD et al., 2013).

Também foi relatado por 5\% dos alunos que os sapos, quando molhados, atrairiam chuvas. Segundo os alunos, seria comum ver estes animais no começo das chuvas. Esta visão é explicada pelo fato de os sapos saírem em busca de parceiros e se reproduzirem nas épocas chuvosas, aproveitando o momento para o acasalamento (HADDAD et al., 2013). Cinco por cento dos alunos também relataram que estatuetas pequenas de sapos, chamadas na cultura japonesa de Kaeru, atraem boa sorte, sendo este um aspecto cultural vindo da cultura japonesa que se integrou à cultura brasileira. "Kaeru" na língua japonesa significa rã e ao mesmo tempo retorno ou retorno para casa (ALISAL et al., 2007). Esses animais também foram utilizados em amuletos contra mal olhado em culturas antigas do Egeu e Mediterrâneo (RAVEN, 1951).

Como aspectos negativos, $2 \%$ dos alunos relataram que sapos são comumente utilizados para bruxarias ou associados às bruxas, e $2 \%$ dos relatos mencionaram que quando um sapo gruda na perna de uma pessoa ele solta apenas na próxima Lua cheia, sendo está uma crença passada geralmente pelos mais velhos dentro da familia. Sapos e rãs são associados há muito tempo com bruxaria, sendo encontrados até mesmo em mitologias do período neolítico, mas a principal relação se estabeleceu à bruxaria de origem europeia, onde se acreditava que as bruxas poderiam assumir a forma desses animais e utilizavam suas toxinas para preparar suas poções. Muitas mitologias relacionaram esses animais à chuva e à Lua. O coaxar ritmado de sapos e rãs também era utilizado por antigas bruxas e suas toxinas usadas por xamãs para induzir estados alterados de consciência (RAVEN, 1951). Muitos povos indígenas da Amazônia, como o povo Mayeruna, no Peru, também utilizam as toxinas tanto para rituais sagrados como para a medicina tradicional (GORMAN, 1990; ERSPAMER et al., 1993).

Doze por cento dos alunos também relataram que ao se jogar sal em um sapo ele queimaria. Por terem pele permeável para trocas eletrolíticas e absorção de água, estes animais se tornam vulneráveis a soluções salinas, sendo poucas as espécies que podem tolerar a salinidade, como anuros do gênero Thoropa (DUELLMAN e TRUEB, 1996). Desta forma, o ato de colocar ou jogar sal sobre sapos lhes causa grande dano. $\mathrm{O}$ ato de desvendar a fisiologia destes animais aos alunos por meio da educação ambiental pode causar maior empatia para evitar agressões aos anfíbios.

Cinco por cento dos alunos relataram que todos os sapos são venenosos, seguidos de $2 \%$ dos alunos que além de achar que sapos são venenosos e sua urina pode causar cegueira; outros $2 \%$ mencionaram que sua urina pode causar queimaduras na pele e $2 \%$ também relataram que, ao se tocar em um sapo, se a mão for levada aos olhos causaria cegueira. Entre os sapos, rãs e pererecas da Mata Atlântica no Brasil, apenas 15\% são considerados tóxicos, como os animais pertencentes às familias 
Bufonidae e Phyllomedusidae, sendo esta toxicidade utilizada unicamente para repelir predadores ou patógenos (HADDAD et al., 2013). A urina destes animais é basicamente composta de ureia (DUELLMAN e TRUEB, 1996), não causando danos à pele ou mucosas.

A reação dos alunos ao encontrar um sapo pode ser dividida em duas classificações: reações não agressivas ( $84 \%$ das respostas) e reações agressivas (16\%) (Figura 1c). Sobre as reações não agressivas: $32 \%$ agiriam normalmente, $25 \%$ se afastariam ou desviariam do animal, $14 \%$ não fariam nada, $7 \%$ só observariam o animal, $4 \%$ não manteriam contato e $2 \%$ chamariam alguma outra pessoa para mudar o animal de lugar. Sobre as reações agressivas ao encontrar um anuro: $9 \%$ gritariam e sairiam de perto, $5 \%$ se assustariam ao encontrar o animal e $2 \%$ chutariam o animal (Figura 1c).

Após a intervenção de educação ambiental, notou-se uma mudança expressiva na atitude dos estudantes caso encontrassem algum sapo (Figura 1d): $87 \%$ dos alunos teriam reações não agressivas ou positivas (28\% não fariam nada, $20 \%$ agiriam normalmente, $14 \%$ colocariam o animal em um lugar seguro, $14 \%$ observariam o animal e $11 \%$ sairiam de perto). Apenas $11 \%$ teriam uma atitude agressiva, sendo que $2 \%$ gritariam, $2 \%$ se assustariam e $7 \%$ sairiam correndo; os outros $2 \%$ restantes não souberam responder.

Quando perguntado aos alunos o que eles fariam caso encontrassem algum sapo em uma ocasião de risco, antes da intervenção de educação ambiental apenas $43 \%$ deles disseram que ajudariam o animal, $34 \%$ não fariam nada, $12 \%$ talvez ajudassem, $9 \%$ correriam e chorariam e $2 \%$ não souberam responder (Figura 1e). Após a atividade de educação ambiental ministrada, $73 \%$ dos alunos ajudariam o animal, $16 \%$ não fariam nada, $7 \%$ talvez ajudassem e $4 \%$ sairiam correndo (Figura 1f).

Com base geral no questionário cultural aplicado aos alunos, podemos notar que muitas lendas e mitos estão presentes na cultura dos alunos, tendo influência pela diversidade cultural do Brasil, com uma heterogeneidade de povos indígenas e imigrantes de diferentes nacionalidades, principalmente de origem europeia e japonesa. Notou-se, também, que muitas das atitudes adotadas ao encontrar um anfíbio são tomadas com base no conhecimento popular e cultura local dos indivíduos avaliados, no caso dos estudantes uma cultura pluriétinica e missigenada, constituida principalmente de imigração italiana para a região. A atividade de educação ambiental ministrada mostrou-se uma ferramenta importante na modificação da concepção que os estudantes têm sobre os anfíbios e suas ações ao se depararem com um sapo, rã ou perereca.

A Figura 2 traz a comparação das questões aplicadas antes e após a intervenção ambiental, onde notou-se uma nítida diferença entre as margens das notas dos questionários aplicados a priori e $a$ posterior da intervenção ambiental sobre ecologia e conservação de anfíbios.

No questionário aplicado a priori os alunos demostraram não compreender ou compreender pouco cinco das seis questões. A última questão refere-se apenas a formas de cooperação que os alunos têm com o meio ambiente e teve em média uma avaliação razoável pelos alunos avaliados. Após a intervenção de educação ambiental, os alunos melhoraram todos os conceitos a respeito dos anfíbios e sua relação com o meio ambiente. A maioria dos alunos compreendeu razoavelmente a diferença entre sapos, rãs e pererecas. Posteriormente à atividade de educação ambiental, os alunos também demostraram ter boa compreensão ou plena compreensão da etnologia da palavra anfíbio (anfítbio = animal de duas vidas, que se deve pela fase larval e terrestre na maioria das espécies), influência que a poluição do habitat tem sobre girinos, função da vocalização, importância ecológica dos anfíbios e iniciativas gerais para contribuir com o meio ambiente. Esta rápida mudança no conhecimento teórico dos alunos demostra o quanto deficiente é o conteúdo sobre ecologia e zoologia, e o papel que a educação ambiental tem para transformar a cultura e visão que jovens têm sobre a fauna. 
A) Em sua opinião, por que algumas pessoas não gostam, ou sentem medo desses animais? (Senso cultural)

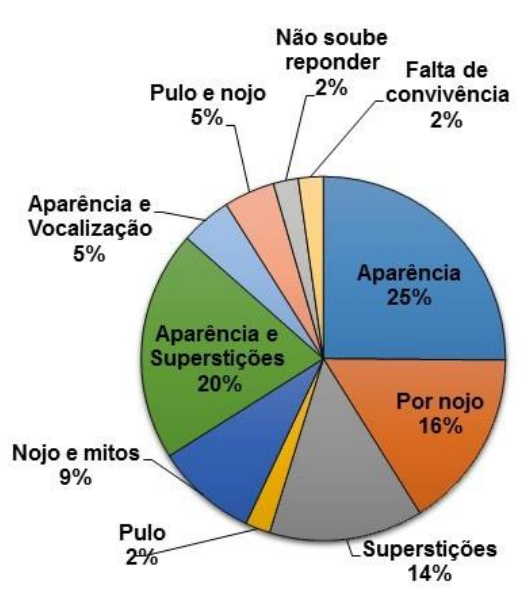

B) Você já ouviu algum mito sobre os sapos? Se sim, qual? (Senso cultural)

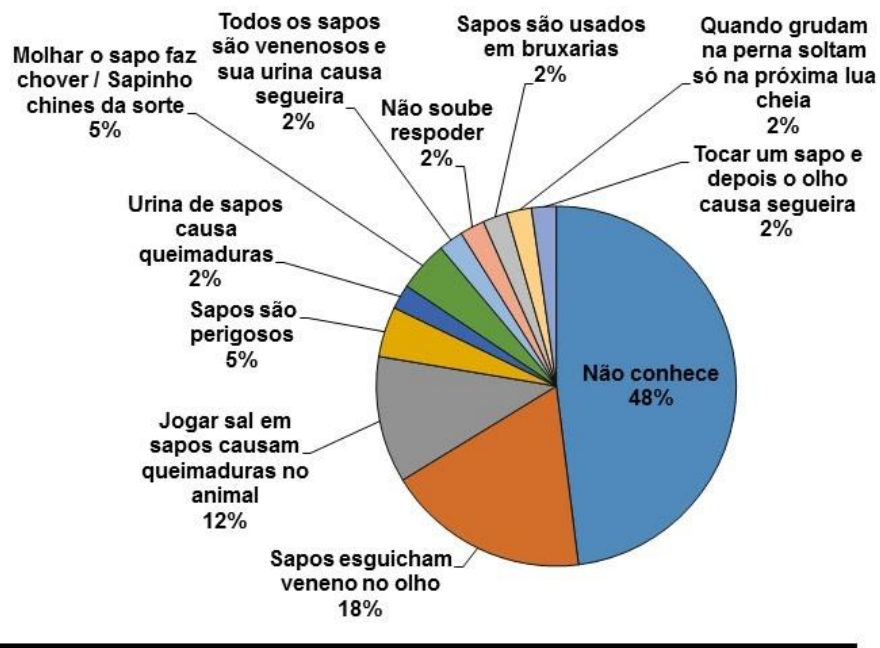

C) Se você se encontrasse um sapo, qual seria sua reação? (Questionário a priori)

D) Se você se encontrasse um sapo, qual seria sua
reação? (Questionário a posteriori)
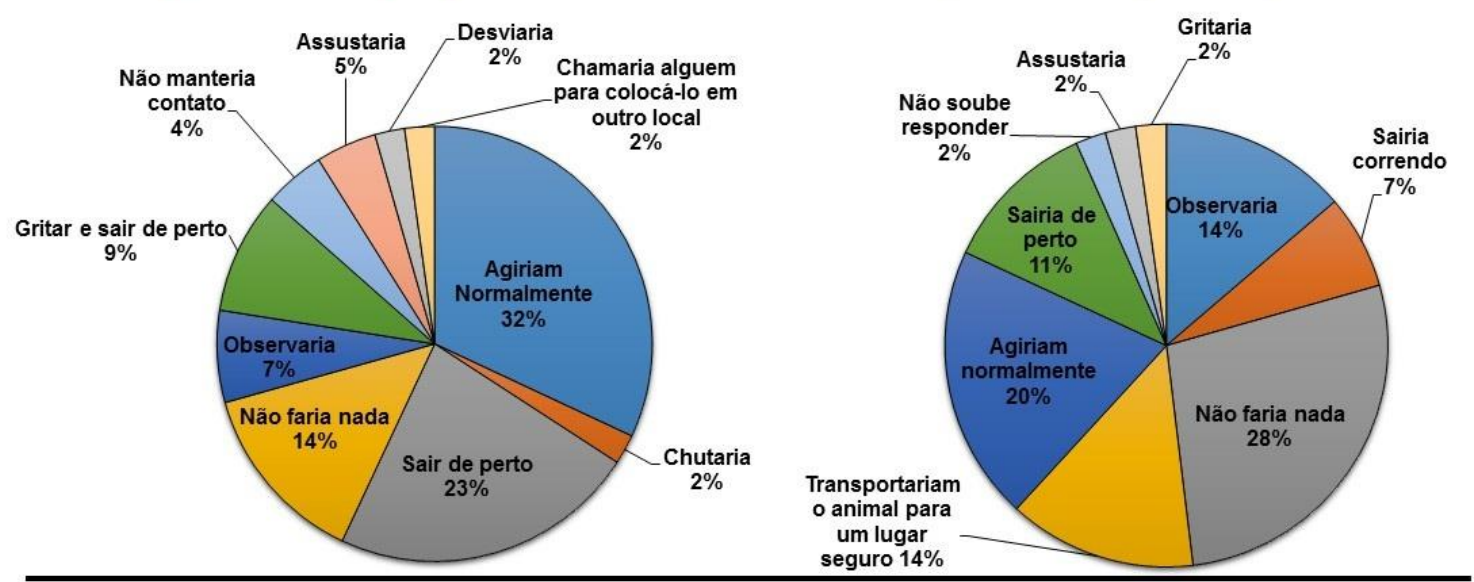

E) Se você encontrasse esses animais em situação de perigo, o que você faria? (Questionário a priori)

F) Se você encontrasse esses animais em situação de
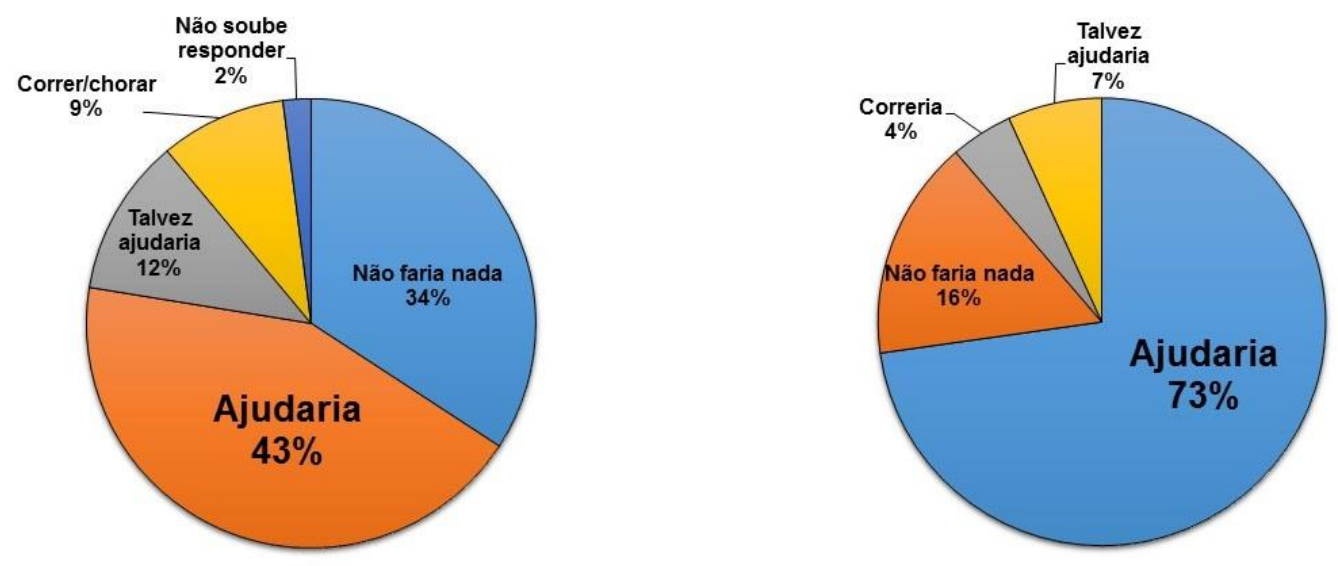

Figura 1 - Comparação antes e depois da intervenção de educação ambiental, entre as perguntas teóricas sobre ecologia de anfíbios e sua relação com o meio ambiente. 
Figura 2: O gráfico demostra os resultados das notas antes (triângulos vermelhos) e depois da intervenção de educação ambiental (auadrados azuis).

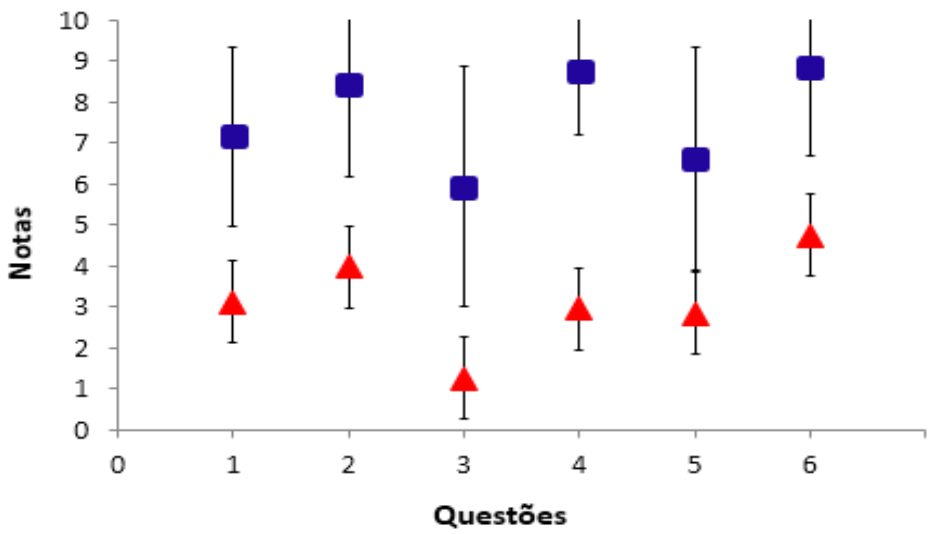

\section{CONCLUSÃO}

Com base na avaliação dos 44 estudantes antes e depois da aplicação dos quiestionários, concluise que muito do conhecimento que os alunos têm sobre os anfíbios é baseado em aspectos culturais, como crenças e mitos, e não em bases científicas. Mediante a isto, observamos que mesmo tendo conteúdos de zoologia, ecologia e ciências ambientais, muitos alunos têm uma visão estigmatizada sobre anfíbios e pouco baseada na biologia desses animais. Neste cenário preocupante, frente às ameaças aos anfíbios, pequenas intervenções de educação ambiental, que abordem a importância ecológica e desvendem aspectos de sua anatomia, preprodução e biologia, podem ter grande poder transformador na visão estigmatizada que muitos têm sobre estes animais, inclusive auxiliando na sua conservação e do meio ambiente como um todo.

Tanto a educação ambiental quanto a científica têm um papel de desconstrução de preconceitos culturais e importância no fortalecimento das bases do conhecimento biológico sobre a fauna. Atividades de educação ambiental, embora pouco difundidas no meio escolar, podem contribuir para a formação de uma geração mais sensível aos problemas ambientais e consciente sobre a necessidade da conservação ambiental.

\section{REFERÊNCIAS}

ALISAL, M. R. et al. Pilgrimages and spiritual quests in Japan. Londres: Taylor \& Francis, 2007.

ANGULO, A.; GRIFFITHS, J. Amphibia. In: BAILLIE, J. E. M. et al. (eds.). Evolution lost: status and trends of the world's vertebrates. Londres: Zological Society of London, 2010.

AZEVEDO-RAMOS, C.; LA MARCA, E.; HOOGMOED, M.; REICHLE, S. Rhaebo guttatus. The IUCN Red List of Threatened Species 2010: e.T54658A11183165. Disponível em: <http://dx.doi.org/10.2305/IUCN.UK.2010-2.RLTS.T54658A11183165.en>. Acesso em 29 mar. 2019.

BOLAÑOS, F. et al. Amphibians of the neotropical realm. In: STUART, S et al. (eds.). Threatened amphibians of the world. Arlington: Conservation International, 2008. p. 92-105.

CASCUDO, L. C. Contos tradicionais do Brasil. São Paulo: Global, 2004.

CORTÉS-GOMEZ A. M. et al. Ecological functions of Neotropical amphibians and reptiles: a review. Universitas Scientiarum, v. 20, p. 229-245, 2015.

COX, N. et al. Why save amphibians? In: In: STUART, S et al. (eds.). Threatened amphibians of the world. Arlington: $\quad$ Conservation $\quad$ International, $2008 . \quad$ p. 23-29. DUELLMAN, W. E; TRUEB, L. Biology of amphibians. Baltimore: The Johns Hopkins University Press, 1996. ERSPAMER, V. et al. Pharmacological studies of 'Sapo' from the frog Phyllomedusa bicolor skin: a drug used by the Peruvian Matses Indians in shamanic hunting practices. Toxicon, v. 31, n. 9, p. 1099-1111, 1993.

FERRANTE, L. Research, ethnobiology and environmental education: integrated actions and strategies for amphibian conservation in Brazilian agricultural landscapes. FrogLog, v. 24, n. 1, p. 30-34, 2016a.

FERRANTE, L. Estratégias para a conservação da herpetofauna por meio de educação ambiental e etnobiologia em fazendas certificadas e áreas rurais. Herpetologia Brasileira, v. 5, n. 1, p. 3-4, 2016 b.

FERRANTE, L. Proceratophrys boiei (smooth horned frog) reproduction. Herpetological Review, in press. 2019.

FERRANTE, L.; NAJAR, T. De girinos a sapos: Instituto Boitatá incentiva jovens a se tornarem futuros cientistas para a conservação da herpetofauna na Amazônia. Herpetologia Brasileira, v. 5, n. 2, p. $27,2016$.

FERRANTE, L. et al. The Matrix Effect: how agricultural matrices shape forest fragment structure and amphibian composition. Journal of Biogeography, v. 44, p. 1911-1922, 2017a. DOI:10.1111/jbi.12951 
FERRANTE, L. et al. Multiple strategies for revealing the Amazonian amphibians: environmental education and conservation actions in Amazonian Forest. Frog Log, v. 25, n. 2, p. 29-30, 2017b.

FERRANTE, L. et al. The local extinction of tree frog Scinax caldarum. Herpetological Journal, in press, 2019a.

FERRANTE, L. et al. The third consecutive year of Save The Frogs Day in the Brazilian Amazon and the experience of working with environmental education. Frog Log, in press, 2019b. 1990.

GORMAN, P. People of the jaguar: shamanic hunting practices of Matses. Shaman's Drum, v. 21, p. 40-50,

HADDAD, C. F. B.; TOLEDO, L. F.; PRADO, C. P. A.; LOEBMANN, D.; GASPARINI, J. L.; SAZIMA, I. Guide to the amphibians of the Atlantic Forest: diversity and biology. São Paulo: Anolis Books, 2013.

IUCN. Lithobates catesbeianus. The IUCN Red List of Threatened Species 2015: e.T58565A53969770. Disponível em <http://dx.doi.org/10.2305/IUCN.UK.2015-

4.RLTS.T58565A53969770.en>. Acesso em: 9 maio 2019.

IUCN. The IUCN Red List of Threatened Species. Version 2015-4. Disponível em: <http://www.iucnredlist.org >. Acesso em: 28 mar. 2019.

JARED, C.; ANTONIAZZI, M. M.; VERDADE, V. K.; TOLEDO, L. F.; RODRIGUES, M. T. The Amazonian toad Rhaebo guttatus is able to voluntarily squirt poison from the paratoid macroglands. Amphibia-Reptilia, v. 32, p. 546-549, 2011.

JENSEN, E. Evaluating children's conservation biology learning at the Zoo. Conservation Biology, v. 28, p. 1004-1011, 2013.

LEITE, C. Cobras e sapos: esses bichos malditos! Um estudo sobre a relação entre saberes populares e saberes acadêmicos na educação ambiental. 2004. Dissertação - Universidade do Porto, Porto, 2004.

NAJAR, T.; FERRANTE, L. The journey of life of the tiger-striped leaf frog Callimedusa tomopterna (Cope, 1868): notes of sexual behaviour, nesting and reproduction in the Brazilian Amazon. Herpetology Notes, v. 11, p. 531-538, 2018.

PONTES-DA-SILVA, E.; PACHECO, M. L. T.; PEQUENO, P. A. C. L. FRANKLIN, E.; KAEFER, I. L. Attitudes towards scorpions and frogs: a survey among teachers and students from schools in the vicinity of an Amazonian protected area. Journal of Ethnobiology, v. 36, n. 2, p. 395-411, 2016.

RAVEN, G. Encyclopedia of Wicca \& witchcraft. Woodbury: Llewellyn Publications, 1951.

SILVANO, D. L. et al. Anfíbios e répteis. In: RAMBALDI, D. M.; OLIVEIRA, D. A. S. (orgs.), Fragmentação de ecossistemas: causas, efeitos sobre a biodiversidade e recomendações de políticas públicas. Brasília: Ministério do Meio Ambiente, 2005. p. 183-200.

WELLS, K. D. The ecology and behavior of amphibians. Chicago: University of Chicago Press, 2007. 